\title{
The use of antidepressants and the risk of chronic atrial fibrillation
}

\author{
Lapi F. PharmD PhD, ${ }^{1}$ Azoulay L. PhD,${ }^{2,3}$ Kezouh A. PhD,${ }^{2}$ Benisty I.J. MD MPH, ${ }^{2}$ Matok I.
}

$$
\text { MsPharm PhD, }{ }^{4} \text { Mugelli A. MD MSc, }{ }^{5} \text { Suissa S. PhD }{ }^{2,6}
$$

${ }^{1}$ Health Search, Italian College of General Practitioners, Florence (Italy);

${ }^{2}$ Centre for Clinical Epidemiology, Lady Davis Institute, Jewish General Hospital, Montreal, Quebec (Canada);

${ }^{3}$ Department of Oncology, McGill University, Montreal, Quebec (Canada);

${ }^{4}$ Institute for Drug Research, School of Pharmacy, Hebrew University, Jerusalem (Israel);

${ }^{5}$ Department of NEUROFARBA, Section of Pharmacology and Toxicology, University of

Florence, Florence (Italy);

${ }^{6}$ Department of Epidemiology, Biostatistics and Occupational Health, McGill University,

Montreal, Quebec (Canada);

Running head: antidepressants and atrial fibrillation

Keywords: antidepressants, serotonin, chronic atrial fibrillation, nested case-control study

Word count: 2921

Abstract word count: 196

Number of figures: 1

Number of tables: 3

Number of references: 42

\section{Financial Disclosures and Conflicts of Interest}

Dr. Suissa has received research grants from AstraZeneca, Boehringer Ingelheim and

GlaxoSmithKline, and has participated in advisory board meetings and as speaker in conferences for AstraZeneca, Boehringer-Ingelheim, GlaxoSmithKline, Novartis, Pfizer and Merck. Dr. Lapi provided consultancies in protocol preparation for epidemiological studies for Menarini, Abbvie, IBSA, Angelini, and Servier. Dr. Azoulay, Dr. Benisty, Dr. Kezouh, Dr. Matok and Dr. Mugelli do not have any conflicts of interest to disclose. 


\section{Corresponding author:}

Dr. Samy Suissa

Centre for Clinical Epidemiology

Lady Davis Institute, Jewish General Hospital

3755 Côte Sainte-Catherine, H-461

Montreal, Quebec, Canada H3T 1E2

Email: samy.suissa@mcgill.ca

Tel: 514-340-7593 Fax: 514-340-7564 


\begin{abstract}
Serotonin stimulation of the 5HT4 receptor might be responsible for an increased risk of atrial fibrillation (AF). Thus, we assessed whether the use of antidepressants (ADs) is associated with an increased risk of chronic AF (cAF). Using the UK Clinical Practice Research Datalink, a nested case-control analysis was conducted within a cohort of new AD users having a diagnosis of depression and/or anxiety. Cases of cAF occurring during follow-up were individually matched with up to 10 controls on age, sex, year of cohort entry, and duration of follow-up. Conditional logistic regression was used to estimate rate ratios (RRs) and 95\% confidence intervals (CIs) of cAF associated with current and recent use of ADs, when compared to past use. The cohort included 116,125 new AD users, of whom 1271 were diagnosed with cAF during follow-up (incidence rate: 1.6 per 1000 person-years). The adjusted RR of cAF associated with current and recent use of ADs was 0.98 (95\% CI: 0.86-1.12) and 1.02 (95\% CI: 0.86-1.30), respectively. No association was observed when ADs were classified according to their potency in reducing serotonin reuptake. These findings suggest that exposure to ADs is not associated with an increased risk of cAF.
\end{abstract}




\section{INTRODUCTION}

Chronic atrial fibrillation (cAF) is the most common disease among the cardiac rhythm disorders. This condition has been associated with increased morbidity and mortality.[1, 2] Preclinical evidence has suggested a role for serotonin 5HT4 receptors in atrial arrhythmias.[3] Indeed, serotonin promotes intracellular calcium overload and increases the amplitude of the pacemaker current $I_{f}$ in atrial myocytes. These alterations are potentially arrhythmogenic and might trigger AF.[4, 5] Furthermore, a greater concentration of mRNA coding 5HT4 receptors has been identified in patients with cAF.[6]

Antidepressants (ADs) exert their therapeutic effect by increasing the endogenic levels of serotonin. Given this mechanism, long-term exposure to ADs might be associated to a higher risk of cAF. The association between the use of these drugs and other arrhythmogenic disorders [7, 8], as well as ischemic stroke (the most common cardiovascular consequence of cAF) have been already investigated.[9, 10] However, no studies have examined the electrophysiological hypothesis to date. The objective of this study was therefore to determine whether the use of ADs is associated with an increased risk of $\mathrm{cAF}$. 


\section{METHODS}

\section{Data source}

We used the United Kingdom (UK) Clinical Practice Research Datalink (CPRD), formerly known as the General Practice Research Database. This is the world's largest computerized database of primary care, which contains the complete medical records for more than 13 million people (corresponding to approximately $8.4 \%$ of the UK population) enrolled in more than 680 general practices. The geographic distribution of the practices participating in the CPRD has been shown to be representative of the UK population, and age and sex distributions of patients in the CPRD are similar to those reported by the National Population Census.[11] The data recorded in the CPRD since 1987 include demographic information, prescription details, clinical events, specialist referrals, along with lifestyle variables comprising body mass index (BMI), smoking habits and alcohol use.[11] A recent review found that medical data in the CPRD are of high quality.[12, 13] Read codes are used to enter medical diagnoses and procedures, which is the standard clinical terminology system used in general practice in the UK, and a coded drug dictionary based on the UK Prescription Pricing Authority Dictionary is used for recording prescriptions.

The study protocol was approved by the Independent Scientific Committee of the CPRD and the Research Ethics Board of the Jewish General Hospital, Montreal, Canada.

\section{Study population}

We identified a cohort of patients, at least 18 years of age, newly-prescribed ADs (agomelatine, amitriptyline, amoxapine, bupropion, butriptyline, citalopram, clomipramine, desipramine, dosulepin, doxepin, duloxetine, escitalopram, fluoxetine, flupentixol, fluphenazine/fluvoxamine, imipramine, iprindole, iproniazid, isocarboxazid, lofepramine, 
maprotiline, mianserin, mirtazapine, moclobemide, nefazodone, nortriptyline, paroxetine, phenelzine/protriptyline, reboxetine, sertraline, tranylcypromine, trazodone, trifluoperazine, trimipramine, tryptophan, venlafaxine, viloxazine) with a prior diagnosis of depression and/or anxiety, registered with an up-to-standard practice between January 1, 1993 and December, 31, 2010. To be eligible, patients were required to have at least one year of medical history in the CPRD prior to cohort entry (date of the first AD prescription), and at least 6 months of followup. The latter criterion was applied in order to ensure that all ADs users were exposed for a sufficiently long period necessary to induce cAF.[14] We also excluded patients with a previous history of AF (both paroxysmal and persistent form), valvular disease or mitral or aortic valve repair or replacement, life-threatening ventricular tachyarrhythmia, cardioversion, implantation of a cardiac defibrillator or pacemaker for $\mathrm{AF}$, cardiac arrest, congenital conduction disorder or advanced cardiomyopathy, stroke, heart infarction, hyperthyroidism, use of anticoagulants and/or antiarrhythmic medications at any time prior to cohort entry.

All patients were followed from the first $\mathrm{AD}$ prescription until the first of the following events: an incident diagnosis of cAF (cases), death from any cause, occurrence of one of the exclusion criteria (except the procedures of implantation of a cardiac defibrillator or pacemaker or those to monitor $\mathrm{AF}$, paroxysmal $\mathrm{AF}$ and use of anticoagulants and/or antiarrhythmic drugs and stroke, because of their clinical relationship with AF diagnosis), end of registration with the general practice, or end of the study period (December, 31, 2011).

\section{Case and control definition}

All cases of cAF occurring during follow-up were identified, using the Read codes used in previous CPRD studies.[1, 15, 16] All codes related to paroxysmal AF and other acute forms of arrhythmia were not considered as part of the case definition. Cases were then coupled with 
specific cardiac surgical or monitoring procedures and interventions (i.e., AF monitoring, ECG confirming a diagnosis of AF or flutter, pacemaker implantation, percutaneous transluminal ablation, chemical or external cardioversion) as well as pharmacological treatments (i.e., anticoagulants or antiarrhythmic drugs). Codes pertaining to cardiac interventions to treat rhythm disorders ( \pm 3 months from the date of diagnosis) and all prescriptions for an antiarrhythmic drug ( \pm 1 months from the date of diagnosis), were examined with respect to each cAF event The index date was then defined as the earlier date from either the diagnosis of cAF or the occurrence of a cAF-related surgical/interventional procedures or pharmacological treatment.

For each case of cAF, up to 10 controls were randomly selected from the case's risk set, matching on year of birth, sex, year of cohort entry, and duration of follow-up. The index date of the cases was assigned to the matched controls.

\section{Exposure assessment}

For all cases and matched controls, we obtained all ADs prescribed between cohort entry and index date. For the primary analysis, the exposure was defined according to three timing of use categories: current use, defined as the last prescription in the 6 months before the index date; recent use, defined as the last prescription in the 6-12 months before the index date; and past use, defined as the last prescription more than 12 months before the index date.

For secondary analyses, exposure was redefined in three ways. First, we evaluated the risk of developing the event among patients currently exposed according to AD class: tricyclic antidepressants (TCA), selective serotonin reuptake inhibitors (SSRIs), mono-amino oxidase (MAO) inhibitors, and other ADs or combinations. Second, current exposure was also subclassified into three mutually-exclusive groups based on inhibitory potency to serotonin reuptake: high-potency (dissociation constant $(\mathrm{Kd})<1 \mathrm{nmol} / \mathrm{L})$, intermediate-potency $(\mathrm{Kd}=1-10$ 
$\mathrm{nmol} / \mathrm{L})$, and low-potency ( $\mathrm{Kd}>10 \mathrm{nmol} / \mathrm{L}) .[17,18]$ Third, we investigated duration of use, degree of adherence, and individual molecules among current users of high-potency ADs. The duration of each prescription was calculated from the number of prescribed tablets combined with dosing instructions. A duration of 28 days was assumed (the mode), when it was not possible to derive exposure duration from the available information. For unusually low or high values of prescription duration we assigned a minimum of 7 or a maximum of 90 days to the prescription duration.[7] Additionally, continuous use was defined as when the duration of one prescription overlapped the date of the next prescription, allowing for a 28-day "grace period" between prescriptions.[19-23] Among overlapping prescriptions, individuals were assumed to have refilled early and not completed the first prescription before starting the second prescription. Thus, duration of use was calculated by summing up the total number of prescribed days. Adherence was expressed as proportion of days covered (PDC), which is derived from dividing the cumulative days of medication use by the length of follow-up. The degree of adherence was categorized as a PDC $<80$ or $\geq 80 \%$.[19, 20, 24]

\section{Potential confounders}

Covariates used for adjustment were identified from factors known to be associated with cAF that could also influence the choice of AD therapy. These included the indications of use (depression, anxiety or both) at cohort entry, heart failure, hypertension, diabetes, chronic obstructive pulmonary disease (COPD) and asthma,[15] all measured at any time before the index date. Excessive alcohol use, smoking status and obesity (BMI $\left.>30 \mathrm{~kg} / \mathrm{m}^{2}\right)$ were defined as the last record before the index date. Covariates also included medications prescribed within a 2year time-window before the index date. These included antihypertensive drugs (i.e., alphablockers, beta-blockers, calcium channel blockers, angiotensin converting-enzyme inhibitors, 
angiotensin receptor blockers, diuretics), statins, anti-inflammatory drugs, acetaminophen, beta2 agonists, corticosteroids, and other respiratory medications.

\section{Statistical analysis}

Given that all cohort members had at least 6 months of follow-up (and thus no events), person-time at risk was calculated starting 6 months after the first AD prescription. The crude incidence rate of $\mathrm{cAF}$ was calculated by dividing the number of cases by the total person-years of follow-up.

Conditional logistic regression was used to compute odds ratios of cAF which, which in the context of a nested case-control analysis, are unbiased estimators of the incidence rate ratio (RR) with 95\% confidence intervals (CI).[25] In addition to age, sex, year of cohort entry, and duration of follow-up on which the logistic regression was conditioned, the models were adjusted for the aforementioned potential confounders. Confounding by indication ${ }^{[26]}$ was minimized because the reference category for all analyses consisted of past users, a group of patients likely sharing several characteristics of current and recent users.

In the primary analysis, we compared the risk of $\mathrm{cAF}$ associated with current and recent use with past use of ADs. In a secondary analysis, we estimated the RRs of cAF among current users of $\mathrm{ADs}$ according to chemical class and potency in reducing serotonin reuptake. Furthermore, among current users of high-potency ADs, we assessed whether the risk of cAF varied according to the duration of use, degree of adherence, and individual molecule.

Finally, two sensitivity analyses were conducted. The first sensitivity analysis addressed issues related to possible misclassification of the outcome. Thus, cases of cAF were restricted to those requiring surgical or monitoring procedures/interventions or pharmacological therapy. In a 
second sensitivity analysis, we varied the current exposure time-window to 2 and 3 months. All analyses were conducted with SAS version 9.2 (SAS Instititute, Cary, NC). 


\section{RESULTS}

A total of 116,125 new users of ADs previously diagnosed with depression and/or anxiety met the study inclusion criteria (Figure 1). At cohort entry, mean age was 43.5 years (SD: 16.2), and most of the patients were female (67.5\%). The cohort members received ADs because of depression (55\%), anxiety (44.6\%) or both (0.4\%). During follow-up, 1270 cases of cAF were identified, generating an overall incidence rate of 1.6/1,000 person-years.

Table 1 depicts the demographic and clinical characteristics of cases and their matched controls. Mean age at cAF was 72.4 (SD: 12.8) and 72.0 (SD: 12.0) in cases and their respective controls; $63.5 \%$ of cases and controls were women (age and sex were matching factors). Moreover, more than half of cases and controls received ADs to treat anxiety. Excessive alcohol use was slightly higher among cases than controls, and cases were more likely to be obese than controls, while no differences were observed in terms of smoking between the two groups.

Cases were more likely to have cardiovascular diseases such as heart failure, hypertension and diabetes, as well as chronic respiratory conditions such as asthma and COPD. Consequently, cases were also more likely to have been using antihypertensives, antiarrhythmics, antithrombotics, lipid-lowering drugs as well as oral corticosteroids and respiratory medications. The use of non-steroidal anti-inflammatory drugs (NSAIDs) and acetaminophen was also greater among cases than controls (Table 1).

Table 2 presents the results of the primary analysis. Compared to past use, the risk of cAF was not increased with either current $(\mathrm{RR}=0.98 ; 95 \% \mathrm{CI}=0.86-1.12)$ or recent use of ADs $(\mathrm{RR}=1.02 ; 95 \% \mathrm{CI}=0.86-1.30)$. When current use was further categorized according to chemical class, no association with cAF was observed among SSRIs users ( $\mathrm{RR}=1.06$; 95\% $\mathrm{CI}=0.89-1.24)$ as well as for TCA ( $R R=0.93 ; 95 \% \mathrm{CI}=0.76-1.13)$ and others $\mathrm{ADs}(\mathrm{RR}=0.80 ; 95 \% \mathrm{CI}=0.59$ 1.10). Similarly, there was no association with potency of ADs. 
Table 3 shows the results of the secondary analyses. Although not statistically significant, current use of high-potency ADs tended to be associated with slightly higher risks with shorter durations of use $(<12$ months: $\mathrm{RR}=1.26 ; 95 \% \mathrm{CI}=0.86-1.83 ; 12$ to 24 months: $\mathrm{RR}=1.22 ; 95 \%$ $\mathrm{CI}=0.80-1.86 ;>24$ months: $\mathrm{RR}=0.88 ; 95 \% \mathrm{CI}=0.67-1.15)$. Similarly, non-adherent patients showed a non-significant higher risk of $\mathrm{cAF}(\mathrm{RR}=1.23 ; 95 \% \mathrm{CI}=0.97-1.57)$ than the adherents $(\mathrm{RR}=0.73 ; 95 \% \mathrm{CI}=0.51-1.02)$. No substantial difference was observed among individual AD molecules (Table 3).

In sensitivity analyses, varying the length of the current time-window to 2 and 3 months produced results similar to the ones observed in the primary analyses (see supplemental Tables 1 and 2). In addition, using a stricter case definition (i.e., limiting cases to those that had surgical procedures/interventions or a pharmacological therapy) generated results consistent with those of the primary analyses (see supplemental Table 3 ). 


\section{DISCUSSION}

In this first population-based study examining the association between ADs and the risk of cAF, we found that the use of ADs does not appear to be associated with an increased risk of cAF, even when the agents were categorized according to their potency in reducing serotonin reuptake.

Several reasons might explain our results. Although some preclinical evidence has correlated the electrophysiological role of 5HT4 serotonin receptors in inducing AF, [4, 5, 27-29] other biological pathways might be more involved in the development of serotonin-related cardiac disease. Specifically, cardiac valvulopathy, which is a leading risk factor for cAF, is one of the major complications in patients with carcinoid syndrome because of serotonin overproduction.[30] Nevertheless, through the stimulation of 5HT2B receptors, as recently demonstrated by some of us,[31] ADs seem unable to act on this pathway.

We adopted a minimum time of 6 months of follow-up because a long-term exposure to high serum serotonin concentration is hypothesized to induce cAF.[14] Nevertheless, the lack of an association for both duration of use and degree of $\mathrm{AD}$ adherence indicate that the increased concentration of serotonin resulting from the pharmacological effect of ADs might not be sufficient to increase the risk of $\mathrm{cAF}$. This is consistent with the fact that ADs seem unable to further increase serotonin levels even in patients already with serotonin overproduction, such as those with carcinoid syndrome [32].

Given that an indirect stimulation of 5HT4 receptors was the biological rationale of our study, the direct binding of ADs to 5HT4 receptors could be more likely to have a causal association with cAF. However, there is no evidence of relevant affinity towards $5 \mathrm{HT} 4$ for any ADs, and also the new medications acting as highly selective 5HT4 agonists (i.e., prucalopride) showed a good cardiovascular safety profile according to recent clinical trials.[33] 
Trifirò and colleagues[34] observed an increased risk of ischemic stroke among users of SSRIs (adjusted $\mathrm{OR}=1.39,95 \% \mathrm{CI}=1.03-1.86$ ). Given that $\mathrm{cAF}$ is a major risk factor for stroke,[35] our study excludes an indirect effect due ADs-related cAF. On the other hand, our results show a non-significant trend of risk reduction of cAF moving from a short to a longer duration of use as well as from a low to a greater degree of adherence to ADs. Possible explanations supporting these results might concern a protective effect of ADs[36-38] towards cAF as well as a "healthy adherer" effect (i.e., better general lifestyle) among adherent patients.[39]

This study has a number of strengths. First, we used a large source population and study size that allowed us to adjust for a number of potential confounders including medical histories and lifestyle information such as smoking, alcohol use and BMI measurements. Second, by assembling a cohort of ADs users, we effectively minimized confounding by indication. Third, both exposure and covariates definitions were time-dependent given the nested case-control design. Fourth, the exposure to ADs was prospectively recorded in the CPRD, thus eliminating the possibility of recall bias. Finally, we performed several sensitivity analyses whose results were consistent with those of the primary analysis.

This study also has some limitations. First, cases of cAF have not been formally validated. Nevertheless, the incidence rate of $\mathrm{CAF}$ produced in this analysis was in line with the data from literature (incidence rate: 1.2 per 1000 person-years [40]). In addition, when the analyses were restricted to cases requiring monitoring or surgical procedure/intervention or pharmacological therapy, the results remained consistent with those of the primary analysis. Secondly, although the 6-month 'current' exposure time-window was biologically consistent with the expected timeframe of $\mathrm{cAF}$ occurrence, there are no conclusive data on this regard. However, we obtained similar results when repeated the analysis by using shorter exposure time 
windows of 2 and 3 months. Thirdly, given that dosage was not consistently entered in the CPRD, we did not conduct a dose analysis, which would have been subject to important exposure misclassifications. Reassuringly, we performed several complementary analyses by potency, duration, and class which confirmed the absence of risk for cAF due to ADs. Finally, ADs use was assessed on the basis of prescription records, thus assuming that patients actually took these medications. While this might be problematic for medications used for acute conditions, it is reasonable to assume that patients regularly renewing prescriptions for ADs are in fact using them.

In summary, our study indicates that the use of ADs is not associated with an increased risk of cAF. In order to significantly reduce the risk of depression recurrences, an effective pharmacotherapy based on ADs might need to reach a duration of use of 48 months.[41] Thus, the absence of an association with cAF in the duration-response analysis was demonstrated by accounting for the potential adverse effects being expected in the chronic course of therapy. These findings confirm that ADs generally possess a good cardiovascular safety profile. As already demonstrated, they appear unable to reduce platelets aggregation [34] or induce cellular fibrosis [31] with clinical consequences, and we showed they do not seem to impair the electrophysiology of atrial myocytes. All this information sounds reassuring particularly against the backdrop in the increasing use of ADs in western countries.[42] Although our findings need to be confirmed, such information could bear clinical relevance in terms of ADs safety profile. 


\section{Acknowledgements}

This study was funded in part by the Canadian Institutes of Health Research (CIHR). Dr. Samy Suissa is the recipient of the James McGill Chair.

All authors participated in the study design. SS acquired the data. FL, LA and AK performed the statistical analyses. FL wrote the initial draft, and all authors critically revised the manuscript. SS had full access to all statistical reports and tables in the study and take responsibility for the integrity of the data and the accuracy of the data analysis. SS is the guarantor for the paper. 


\section{References}

1 Rietbrock S, Heeley E, Plumb J, van Staa T (2008) Chronic atrial fibrillation: Incidence, prevalence, and prediction of stroke using the Congestive heart failure, Hypertension, Age $>75$, Diabetes mellitus, and prior Stroke or transient ischemic attack (CHADS2) risk stratification scheme. Am Heart J 156 (1): 57-64 DOI 10.1016/j.ahj.2008.03.010

2 Diringer MN, Edwards DF, Mattson DT, Akins PT, Sheedy CW, Hsu CY, Dromerick AW (1999) Predictors of acute hospital costs for treatment of ischemic stroke in an academic center. Stroke 30 (4): 724-728

3 Kaumann AJ (1994) Do human atrial 5-HT4 receptors mediate arrhythmias? Trends Pharmacol Sci 15 (12): 451-455

$4 \quad$ Porciatti F, Pelzmann B, Cerbai E, Schaffer P, Pino R, Bernhart E, Koidl B, Mugelli A (1997) The pacemaker current I(f) in single human atrial myocytes and the effect of beta-adrenoceptor and A1adenosine receptor stimulation. Br J Pharmacol 122 (5): 963-969 DOI 10.1038/sj.bjp.0701473

5 Pino R, Cerbai E, Calamai G, Alajmo F, Borgioli A, Braconi L, Cassai M, Montesi GF, Mugelli A (1998) Effect of 5-HT4 receptor stimulation on the pacemaker current I(f) in human isolated atrial myocytes. Cardiovasc Res 40 (3): 516-522

6 Langer C, Piper C, Vogt J, Heintze J, Butz T, Lindner O, Burchert W, Kersting C, Horstkotte D (2007) Atrial fibrillation in carcinoid heart disease: The role of serotonin. A review of the literature. Clin Res Cardiol 96 (2): 114-118 DOI 10.1007/s00392-006-0463-y

7 Martinez C, Assimes TL, Mines D, Dell'aniello S, Suissa S (2010) Use of venlafaxine compared with other antidepressants and the risk of sudden cardiac death or near death: a nested case-control study. Bmj 340: c249 DOI bmj.c249 [pii]

\subsection{6/bmj.c249}

8 Moore M, Yuen HM, Dunn N, Mullee MA, Maskell J, Kendrick T (2009) Explaining the rise in antidepressant prescribing: a descriptive study using the general practice research database. Bmj 339: b3999 DOI bmj.b3999 [pii]

\subsection{6/bmj.b3999}

9 Chen Y, Guo JJ, Li H, Wulsin L, Patel NC (2008) Risk of cerebrovascular events associated with antidepressant use in patients with depression: a population-based, nested case-control study. Ann Pharmacother 42 (2): 177-184 DOI 10.1345/aph.1K369

10 Smoller JW, Allison M, Cochrane BB, Curb JD, Perlis RH, Robinson JG, Rosal MC, Wenger NK, Wassertheil-Smoller S (2009) Antidepressant use and risk of incident cardiovascular morbidity and mortality among postmenopausal women in the Women's Health Initiative study. Arch Intern Med 169 (22): 2128-2139 DOI 10.1001/archinternmed.2009.436

11 Garcia Rodriguez LA, Perez Gutthann S (1998) Use of the UK General Practice Research Database for pharmacoepidemiology. Br J Clin Pharmacol 45 (5): 419-425

12 Herrett E, Thomas SL, Schoonen WM, Smeeth L, Hall AJ (2010) Validation and validity of diagnoses in the General Practice Research Database: a systematic review. Br J Clin Pharmacol 69 (1): 4 14 DOI 10.1111/j.1365-2125.2009.03537.x

13 Khan NF, Harrison SE, Rose PW (2010) Validity of diagnostic coding within the General Practice Research Database: a systematic review. Br J Gen Pract 60 (572): e128-136 DOI 10.3399/bjgp10X483562

14 Smith SA, Waggoner AD, de las Fuentes L, Davila-Roman VG (2009) Role of serotoninergic pathways in drug-induced valvular heart disease and diagnostic features by echocardiography. Journal of the American Society of Echocardiography : official publication of the American Society of Echocardiography 22 (8): 883-889 DOI 10.1016/j.echo.2009.05.002 
15 Hodgkinson JA, Taylor CJ, Hobbs FD (2011) Predictors of incident atrial fibrillation and influence of medications: a retrospective case-control study. Br J Gen Pract 61 (587): e353-361 DOI 10.3399/bjgp11X578034

16 Azoulay L, Dell'aniello S, Simon TA, Langleben D, Renoux C, Suissa S (2012) A net clinical benefit analysis of warfarin and aspirin on stroke in patients with atrial fibrillation: a nested case-control study. BMC Cardiovasc Disord 12 (1): 49 DOI 10.1186/1471-2261-12-49

17 Tatsumi M, Groshan K, Blakely RD, Richelson E (1997) Pharmacological profile of antidepressants and related compounds at human monoamine transporters. European journal of pharmacology 340 (2-3): 249-258

18 Vaishnavi SN, Nemeroff CB, Plott SJ, Rao SG, Kranzler J, Owens MJ (2004) Milnacipran: a comparative analysis of human monoamine uptake and transporter binding affinity. Biological psychiatry 55 (3): 320-322

19 Karve S, Cleves MA, Helm M, Hudson TJ, West DS, Martin BC (2009) Good and poor adherence: optimal cut-point for adherence measures using administrative claims data. Curr Med Res Opin 25 (9): 2303-2310 DOI 10.1185/03007990903126833

20 Karve S, Cleves MA, Helm M, Hudson TJ, West DS, Martin BC (2009) Prospective validation of eight different adherence measures for use with administrative claims data among patients with schizophrenia. Value Health 12 (6): 989-995 DOI 10.1111/j.1524-4733.2009.00543.x

21 Liu X, Tepper PG, Able SL (2011) Adherence and persistence with duloxetine and hospital utilization in patients with major depressive disorder. Int Clin Psychopharmacol 26 (3): 173-180 DOI 10.1097/YIC.0b013e328343ba1e

22 Peterson AM, Nau DP, Cramer JA, Benner J, Gwadry-Sridhar F, Nichol M (2007) A checklist for medication compliance and persistence studies using retrospective databases. Value Health 10 (1): 3-12 DOI 10.1111/j.1524-4733.2006.00139.x

23 Wu CH, Farley JF, Gaynes BN (2012) THE ASSOCIATION BETWEEN ANTIDEPRESSANT DOSAGE TITRATION AND MEDICATION ADHERENCE AMONG PATIENTS WITH DEPRESSION. Depress Anxiety DOI 10.1002/da.21952

24 Aguglia E, Ravasio R, Simonetti M, Pecchioli S, Mazzoleni F (2012) Use and treatment modalities for SSRI and SNRI antidepressants in Italy during the period 2003-2009. Curr Med Res Opin DOI 10.1185/03007995.2012.713341

25 Breslow NE (1996) Statistics in epidemiology: the case-control study. J Am Stat Assoc 91 (433): 14-28

26 Salas M, Hofman A, Stricker BH (1999) Confounding by indication: an example of variation in the use of epidemiologic terminology. Am J Epidemiol 149 (11): 981-983

27 Pau D, Workman AJ, Kane KA, Rankin AC (2007) Electrophysiological and arrhythmogenic effects of 5-hydroxytryptamine on human atrial cells are reduced in atrial fibrillation. J Mol Cell Cardiol 42 (1): 54-62 DOI 10.1016/j.yjmcc.2006.08.007

28 Kaumann AJ, Gaster LM, King FD, Brown AM (1994) Blockade of human atrial 5-HT4 receptors by SB 207710, a selective and high affinity 5-HT4 receptor antagonist. Naunyn Schmiedebergs Arch Pharmacol 349 (5): 546-548

29 Morgan O, Griffiths C, Majeed A (2008) Antidepressant prescribing and changes in antidepressant poisoning mortality and suicide in England, 1993-2004. J Public Health (Oxf) 30 (1): 6068 DOI 10.1093/pubmed/fdm085

30 Druce M, Rockall A, Grossman AB (2009) Fibrosis and carcinoid syndrome: from causation to future therapy. Nature reviews Endocrinology 5 (5): 276-283 DOI 10.1038/nrendo.2009.51

31 Lapi F, Nicotra F, Scotti L, Vannacci A, Thompson M, Pieri F, Mugelli N, Zambon A, Corrao G, Mugelli A, Rubino A (2012) USE OF ANTIDEPRESSANT SEROTONINERGIC MEDICATIONS AND CARDIAC VALVULOPATHY: A NESTED CASE-CONTROL STUDY IN THE HEALTH IMPROVEMENT NETWORK (THIN) DATABASE. Br J Clin Pharmacol DOI 10.1111/j.13652125.2012.04224.x 
32 Williams MD, Dolenc TJ (2005) Selective serotonin reuptake inhibitors and patients with carcinoid tumor. Psychosomatics 46 (4): 370-372 DOI 10.1176/appi.psy.46.4.370

33 Tack J, Camilleri M, Chang L, Chey WD, Galligan JJ, Lacy BE, Muller-Lissner S, Quigley EM, Schuurkes J, De Maeyer JH, Stanghellini V (2012) Systematic review: cardiovascular safety profile of 5HT(4) agonists developed for gastrointestinal disorders. Aliment Pharmacol Ther 35 (7): 745-767 DOI 10.1111/j.1365-2036.2012.05011.x

34 Trifiro G, Dieleman J, Sen EF, Gambassi G, Sturkenboom MC (2010) Risk of ischemic stroke associated with antidepressant drug use in elderly persons. J Clin Psychopharmacol 30 (3): 252-258 DOI 10.1097/JCP.0b013e3181dca10a

35 Ruigomez A, Garcia Rodriguez LA, Johansson S, Wallander MA, Edvardsson N (2007) Risk of cerebrovascular accident after a first diagnosis of atrial fibrillation. Clin Cardiol 30 (12): 624-628 DOI $10.1002 /$ clc. 20178

36 Lesperance F, Frasure-Smith N (2007) Depression and heart disease. Cleve Clin J Med 74 Suppl 1: S63-66

37 Lichtman JH, Bigger JT, Jr., Blumenthal JA, Frasure-Smith N, Kaufmann PG, Lesperance F, Mark DB, Sheps DS, Taylor CB, Froelicher ES (2009) AHA science advisory. Depression and coronary heart disease. Recommendations for screening, referral, and treatment. A science advisory from the American Heart Association Prevention Committee to the Council on Cardiovascular Nursing, Council on Clinical Cardiology, Council on Epidemiology and Prevention, and Interdisciplinary Council on Quality of Care Outcomes Research. Endorsed by the American Psychiatric Association. Prog Cardiovasc Nurs 24 (1): 19-26 DOI 10.1111/j.1751-7117.2009.00028.x

38 Lichtman JH, Bigger JT, Jr., Blumenthal JA, Frasure-Smith N, Kaufmann PG, Lesperance F, Mark DB, Sheps DS, Taylor CB, Froelicher ES (2008) Depression and coronary heart disease: recommendations for screening, referral, and treatment: a science advisory from the American Heart Association Prevention Committee of the Council on Cardiovascular Nursing, Council on Clinical Cardiology, Council on Epidemiology and Prevention, and Interdisciplinary Council on Quality of Care and Outcomes Research: endorsed by the American Psychiatric Association. Circulation 118 (17): 17681775 DOI 10.1161/CIRCULATIONAHA.108.190769

39 Andersohn F, Willich SN (2009) The healthy adherer effect. Arch Intern Med 169 (17): 16351636; author reply 1636 DOI 10.1001/archinternmed.2009.324

40 Ruigomez A, Johansson S, Wallander MA, Rodriguez LA (2002) Incidence of chronic atrial fibrillation in general practice and its treatment pattern. J Clin Epidemiol 55 (4): 358-363

41 Mann JJ (2005) The medical management of depression. N Engl J Med 353 (17): 1819-1834 DOI 10.1056/NEJMra050730

42 Olfson M, Marcus SC (2009) National patterns in antidepressant medication treatment. Arch Gen Psychiatry 66 (8): 848-856 DOI 10.1001/archgenpsychiatry.2009.81 
Table 1 Characteristics of cases of chronic atrial fibrillation and their matched controls*

\begin{tabular}{|c|c|c|}
\hline Characteristic & $\begin{array}{l}\text { Cases } \\
(n=1271)\end{array}$ & $\begin{array}{l}\text { Controls } \\
(n=12,710)\end{array}$ \\
\hline Age, mean (SD), y & $72.4(12.8)$ & $72.0(12.5)$ \\
\hline Follow-up, mean (SD), y & $5.8(3.8)$ & $5.8(3.8)$ \\
\hline Gender, female & 36.5 & 36.5 \\
\hline Excessive alcohol use & 11.0 & 9.0 \\
\hline \multicolumn{3}{|l|}{ Smoking status } \\
\hline Current & 13.9 & 13.9 \\
\hline Former & 26.4 & 22.5 \\
\hline Never & 50.8 & 53.7 \\
\hline Unknown & 8.9 & 9.9 \\
\hline \multicolumn{3}{|l|}{ BMI } \\
\hline$<30$ & 74.3 & 83.3 \\
\hline$\geq 30$ & 25.7 & 16.7 \\
\hline Unknown & 11.9 & 15.0 \\
\hline \multicolumn{3}{|l|}{ Indication of $A D$ use } \\
\hline Anxiety & 53.9 & 54.1 \\
\hline Depression & 45.8 & 45.6 \\
\hline Both & 0.3 & 0.3 \\
\hline \multicolumn{3}{|l|}{ Comorbidities } \\
\hline Heart failure & 12.3 & 3.0 \\
\hline Hypertension & 49.2 & 39.8 \\
\hline Diabetes & 11.2 & 8.5 \\
\hline COPD & 23.1 & 16.6 \\
\hline Asthma & 16.6 & 12.5 \\
\hline \multicolumn{3}{|l|}{ Co-medications } \\
\hline Antihypertensives & 62.9 & 44.7 \\
\hline Antiarrhythmics & 12.8 & 6.9 \\
\hline Antithrombotics & 49.7 & 21.7 \\
\hline Lipid lowering drugs & 20.8 & 18.0 \\
\hline NSAIDs & 7.4 & 6.6 \\
\hline Paracetamol & 58.0 & 49.7 \\
\hline Oral corticosteroids & 21.4 & 14.9 \\
\hline Respiratory medications & 27.2 & 18.2 \\
\hline
\end{tabular}

Abbreviations: SD: standard deviation; ADs: antidepressants; COPD: chronic obstructive pulmonary disease; NSAIDs: nonsteroidal anti-inflammatory drugs; BMI: Body Mass Index

*Data are presented as \% (denominator at the top of column for cases and controls), unless otherwise indicated. 
Table 2 Crude and adjusted rate ratios of chronic atrial fibrillation associated with the use of antidepressant, classified according to recency of use and chemical class*

\begin{tabular}{llllll}
\hline & $\begin{array}{l}\text { Cases } \\
\mathbf{N = 1 2 7 1}\end{array}$ & $\begin{array}{l}\text { Controls } \\
\mathbf{N = 1 2} \mathbf{2 7 1}\end{array}$ & Crude RR & Adjusted RR & 95\% CI \\
\hline $\begin{array}{l}\text { Recency of use } \\
\text { Past use }\end{array}$ & $665(52.3)$ & $6894(54.4)$ & 1.00 & Reference & Reference \\
$\quad \begin{array}{l}\text { Current use } \\
\text { Recent use }\end{array}$ & $429(38.7)$ & $4740(37.3)$ & 1.08 & 0.98 & $0.86-1.12$ \\
& $114(9.0)$ & $1076(8.5)$ & 1.13 & 1.02 & $0.86-1.30$ \\
Chemical class & & & & & \\
TCA & $151(11.9)$ & $1554(12.0)$ & 1.04 & 0.93 & $0.76-1.13$ \\
SSRIs & $254(20.0)$ & $2310(18.2)$ & 1.15 & 1.06 & $0.89-1.24$ \\
Others & $50(3.9)$ & $617(4.9)$ & 0.85 & 0.80 & $0.59-1.10$ \\
Combinations & $37(2.9)$ & $289(2.3)$ & 1.34 & 1.07 & $0.73-1.59$ \\
& & & & & \\
Potency in reducing serotonin reuptake & & & & \\
LPISR & $98(7.7)$ & $1088(8.6)$ & 0.94 & 0.90 & $0.71-1.14$ \\
IPISR & $217(17.1)$ & $2044(16.1)$ & 1.11 & 0.98 & $0.82-1.16$ \\
HPISR & $140(11.0)$ & $1320(10.4)$ & 1.11 & 1.02 & $0.83-1.25$ \\
Combinations & $37(2.9)$ & $288(2.3)$ & 1.34 & 1.10 & $0.75-1.61$ \\
\hline
\end{tabular}

Abbreviations: TCA=tricyclic antidepressant; SSRIs=selective serotonin reuptake inhibitors; LPISR=low potency inhibitors of serotonin reuptake; IPISR: intermediate potency inhibitors of serotonin reuptake; HPISR: high potency inhibitors of serotonin reuptake.

${ }^{*}$ Data are presented as n (\%; denominator at the top of column for cases and controls) and RR (Rate Ratio) with 95\% Confidence Intervals (CI).

${ }^{* *}$ Adjusted for covariates listed in Table 1.

${ }^{* * *}$ Current use: within 6 months before the index date; recent use: from 6 to 12 months before the Index date; past use: more than 12 months before the index date. 
Table 3 Crude and adjusted rate ratios of chronic atrial fibrillation associated with 'current' users of high-potency antidepressants according to cumulative use, degree of adherence, and individual molecules*

\begin{tabular}{|c|c|c|c|c|c|}
\hline & $\begin{array}{l}\text { Cases } \\
\mathrm{N}=1271\end{array}$ & $\begin{array}{l}\text { Controls } \\
\mathrm{N}=12271\end{array}$ & Crude RR & Adjusted $\mathbf{R R}^{* *}$ & $95 \%$ CI \\
\hline Past use & 665 (52.3) & $6894(54.4)$ & 1.00 & Reference & Reference \\
\hline \multicolumn{6}{|l|}{ HPISR } \\
\hline \multicolumn{6}{|l|}{ Cumulative use } \\
\hline$<12$ months & $41(3.2)$ & 337 (2.7) & 1.34 & 1.26 & $0.86-1.83$ \\
\hline 12-24 months & $29(2.3)$ & $253(2.0)$ & 1.21 & 1.22 & $0.80-1.86$ \\
\hline$>24$ months & $70(5.5)$ & $730(5.7)$ & 0.99 & 0.88 & $0.67-1.15$ \\
\hline \multicolumn{6}{|l|}{ Adherence $^{* * *}$} \\
\hline$<80 \%$ & $97(7.6)$ & $992(6.2)$ & 1.28 & 1.23 & $0.97-1.57$ \\
\hline$\geq 80 \%$ & $43(3.4)$ & $528(4.2)$ & 0.85 & 0.73 & $0.52-1.02$ \\
\hline \multicolumn{6}{|c|}{ Individual molecule } \\
\hline Clomipramine & $4(0.3)$ & $47(0.4)$ & 0.89 & 0.82 & $0.29-1.36$ \\
\hline Duloxetine & $2(0.2)$ & $14(0.1)$ & 1.48 & 1.29 & $0.26-6.40$ \\
\hline Fluoxetine & $48(3.8)$ & $521(4.1)$ & 0.96 & 0.87 & $0.63-1.20$ \\
\hline Paroxetine & $51(4.0)$ & $470(3.7)$ & 1.13 & 1.10 & $0.80-1.51$ \\
\hline Sertraline & $35(2.8)$ & $268(2.1)$ & 1.37 & 1.22 & $0.83-1.81$ \\
\hline Combinations & $37(2.9)$ & $288(2.3)$ & 1.34 & 1.10 & $0.75-1.61$ \\
\hline
\end{tabular}

Abbreviations: HPISR=high potency inhibitors of serotonin reuptake

${ }^{*}$ Data are presented as n (\%; denominator at the top of column for cases and controls) and RR (Rate Ratio) with 95\% Confidence Intervals (CI); current use: within 6 months before the index date; recent use: from 6 to 12 months before the index date; past use: more than 12 months before the index date.

${ }^{*}$ Adjusted for covariates reported in Table 1.

*** Proportion of Days Covered (PDC) during follow-up. 
Supplemental Table S1 Crude and adjusted rate ratios of chronic atrial fibrillation according to the recency of use of antidepressants, their chemical class and degree of potency in reducing serotonin reuptake (current time-window: 3 months)*

\begin{tabular}{llllll}
\hline & Cases & Controls & & \\
& $\mathrm{N}=1271$ & $\mathrm{~N}=12271$ & & \\
& & & & & \\
\hline Recency of use & & & & \\
Past use & $779(61.3)$ & $7970(54.2)$ & 1.00 & Reference & Reference \\
Current Use & $426(33.5)$ & $4148(32.6)$ & 1.05 & 0.97 & $0.84-1.10$ \\
Recent use & $66(5.2)$ & $592(4.7)$ & 1.15 & 1.07 & $0.80-1.42$
\end{tabular}

Chemical class

$\begin{array}{lccccc}\text { TCA } & 127(10.0) & 1281(10.1) & 1.02 & 0.92 & 0.75-1.14 \\ \text { SSRIs } & 220(17.3) & 2027(16.0) & 1.11 & 1.03 & 0.87-1.21 \\ \text { Others } & 43(3.4) & 571(4.5) & 0.77 & 0.76 & 0.54-1.06 \\ \text { Combinations } & 36(2.8) & 269(2.1) & 1.38 & 1.13 & 0.77-1.65\end{array}$

Potency in reducing serotonin reuptake

$\begin{array}{lccccc}\text { LPISR } & 84(6.6) & 965(7.6) & 0.89 & 0.87 & 0.68-1.11 \\ \text { IPISR } & 191(15.0) & 1768(13.9) & 1.11 & 0.99 & 0.83-1.18 \\ \text { HPISR } & 115(9.1) & 1146(9.0) & 1.03 & 0.96 & 0.77-1.19 \\ \text { Combinations } & 36(2.8) & 269(2.1) & 1.38 & 1.16 & 0.79-1.70\end{array}$

Abbreviations: ADs=AntiDepressants; TCA=TriCyclic Antidepressant; SSRIs=Selective Serotonin Reuptake Inhibitors; LPISR=Low Potency Inhibitors of Serotonin Reuptake; IPISR: Intermediate Potency Inhibitors of Serotonin Reuptake; HPISR: High Potency Inhibitors of Serotonin Reuptake.

*Data are presented as n (\%; denominator at the top of column for cases and controls) and RR (Rate Ratio) with 95\% Confidence Intervals (CI).

${ }^{* *}$ Adjusted for covariates listed in Table 1. 
Supplemental Table S2 Crude and adjusted rate ratios of chronic atrial fibrillation according to the recency of use of antidepressants, their chemical class and degree of potency in reducing serotonin reuptake (current time-window: 2 months)*

\begin{tabular}{|c|c|c|c|c|c|}
\hline & $\begin{array}{l}\text { Cases } \\
\mathrm{N}=1271\end{array}$ & $\begin{array}{l}\text { Controls } \\
N=12271\end{array}$ & Crude RR & Adjusted RR ${ }^{* *}$ & $95 \% \mathrm{Cl}$ \\
\hline \multicolumn{6}{|l|}{ Recency of use } \\
\hline Past use & $826(65.0)$ & $8330(65.5)$ & 1.00 & Reference & Reference \\
\hline Current Use & $392(30.8)$ & $3766(29.6)$ & & 0.97 & $0.85-1.11$ \\
\hline Recent use & $53(4.2)$ & $614(4.8)$ & 0.87 & 0.85 & $0.63-1.15$ \\
\hline \multicolumn{6}{|l|}{ Chemical class } \\
\hline TCA & $115(9.1)$ & $1141(9.0)$ & 1.02 & 0.93 & $0.75-1.16$ \\
\hline SSRIS & $201(15.8)$ & $1843(14.5)$ & 1.10 & 1.02 & $0.86-1.21$ \\
\hline Others & $42(3.3)$ & $531(4.2)$ & 0.80 & 0.79 & $0.56-1.11$ \\
\hline Combinations & $4(2.7)$ & $251(2.0)$ & 1.37 & 1.18 & $0.80-1.74$ \\
\hline \multicolumn{6}{|c|}{ Potency in reducing serotonin reuptake } \\
\hline LPISR & $79(6.2)$ & $881(6.9)$ & 0.90 & 0.90 & $0.70-1.16$ \\
\hline IPISR & $170(13.4)$ & $1610(12.7)$ & 1.07 & 0.95 & $0.79-1.15$ \\
\hline HPISR & $108(8.5)$ & $1026(8.1)$ & 1.06 & 0.99 & $0.79-1.15$ \\
\hline Combinations & $35(2.8)$ & $249(2.0)$ & 1.42 & 1.25 & $0.85-1.85$ \\
\hline
\end{tabular}

Abbreviations: ADs=AntiDepressants; TCA=TriCyclic Antidepressant; SSRIs=Selective Serotonin Reuptake Inhibitors; LPISR=Low Potency Inhibitors of Serotonin Reuptake; IPISR: Intermediate Potency Inhibitors of Serotonin Reuptake; HPISR: High Potency Inhibitors of Serotonin Reuptake. 
${ }^{*}$ Data are presented as n (\%; denominator at the top of column for cases and controls) and RR (Rate Ratio) with $95 \%$ Confidence Intervals (CI).

${ }^{* *}$ Adjusted for covariates listed in Table 1. 
Supplemental Table S3 Crude and adjusted rate ratios of chronic atrial fibrillation according to the recency of use of antidepressants, their chemical class and degree of potency in reducing serotonin reuptake (cases of chronic atrial fibrillation requiring procedure/intervention or pharmacological therapy)*

\begin{tabular}{|c|c|c|c|c|c|}
\hline & $\begin{array}{l}\text { Cases } \\
\mathrm{N}=821\end{array}$ & $\begin{array}{l}\text { Controls } \\
\mathrm{N}=8210\end{array}$ & Crude RR & Adjusted $^{* *}$ RR & $95 \% \mathrm{Cl}$ \\
\hline \multicolumn{6}{|l|}{ Recency of use } \\
\hline Past use & $447(54.5)$ & $4560(55.5)$ & 1.00 & ne & Reference \\
\hline Current Use & $306(37.3)$ & $2992(36.4)$ & & 0.94 & $0.80-1.12$ \\
\hline Recent use & $68(8.3)$ & $658(8.0)$ & 1.07 & 0.98 & $0.71-1.35$ \\
\hline \multicolumn{6}{|l|}{ Chemical class } \\
\hline TCA & 93 (11.3) & 941 (11.5) & 1.01 & 0.88 & $0.68-1.13$ \\
\hline SSRIS & $166(20.2)$ & 1470 (17.9) & 1.16 & 1.07 & $0.87-1.32$ \\
\hline Others & $28(3.4)$ & $385(4.7)$ & 0.75 & 0.73 & $0.48-1.11$ \\
\hline Combinations & $19(2.3)$ & $196(2.4)$ & 0.99 & 0.76 & $0.45-1.28$ \\
\hline \multicolumn{6}{|c|}{ Potency in reducing serotonin reuptake } \\
\hline LPISR & $54(6.6)$ & $653(8.0)$ & 0.84 & 0.83 & $0.60-1.14$ \\
\hline IPISR & $150(18.3)$ & $1342(16.4)$ & 1.15 & 1.01 & $0.81-1.25$ \\
\hline HPISR & $83(10.1)$ & 805 (9.8) & 1.05 & 0.97 & $0.74-1.27$ \\
\hline Combinations & $19(2.3)$ & $192(2.3)$ & 1.01 & 0.75 & $0.44-1.28$ \\
\hline
\end{tabular}

Abbreviations: ADs=AntiDepressants; TCA=TriCyclic Antidepressant; SSRIs=Selective Serotonin Reuptake Inhibitors; LPISR=Low Potency Inhibitors of Serotonin Reuptake; IPISR: Intermediate Potency Inhibitors of Serotonin Reuptake; HPISR: High Potency Inhibitors of Serotonin Reuptake.

${ }^{*}$ Data are presented as n (\%; denominator at the top of column for cases and controls) and RR (Rate Ratio) with 95\% Confidence Intervals (CI). 
${ }^{* *}$ Adjusted for covariates reported in Table 1. 